\title{
Una aproximación a la narrativa audiovisual desde los estudios literarios. Formas dialogales y formas monologales en el informativo de televisión.
}

\author{
Cristóbal Ruitiña \\ Universidad de Oviedo \\ http://dx.doi.org/10.12795/AdMIRA.2011.01.03
}

\begin{abstract}
Resumen
El artículo muestra algunas de las conclusiones de la tesis doctoral del autor, consistente en un análisis narratológico de un informativo de televisión. En concreto, evidencia el recurso a determinadas formas dialogales y monologales en el tipo de texto analizado. A lo largo del artículo, y al contrario de lo que sucede en otros textos audiovisuales, se confirma el predominio del monólogo sobre el diálogo.
\end{abstract}

\section{Palabras Clave}

Narrativa, audiovisual, televisión, monólogo, diálogo

\begin{abstract}
The article shows some of the conclusions of the doctoral thesis of the author, consisting of an narratological analysis of the news program one of television. In I make concrete, it demonstrates the resource to certain forms compose in a dialogue them and soliloquize them in the type of analyzed text. Along the article, and unlike what happens in other audio-visual texts, the predominance of the monologue is confirmed on the dialog.
\end{abstract}

\section{Key Words}

Narrative, audio-visual, television, monologue, dialog

\section{Los estudios literarios y los estudios periodísticos.}

Fenómenos que, en principio, entran dentro del campo de los estudios periodísticos también se pueden analizar desde perspectivas teóricas procedentes de los estudios literarios. Los ejemplos son cada vez más abundantes. Autores como Albert Chillón (1994a) han llegado a proponer el método del Comparatismo Periodístico-Literario, entendido como una derivación de la Literatura Comparada. Este enfoque permite, a juicio de este autor, el análisis de las relaciones intermediáticas, entendidas como aquellas que se producen entre dos textos dados, siendo al menos uno de los dos no estrictamente lingüístico, es decir, que puede ser visual o, como es el caso, audiovisual. Este camino es el que ha procurado 
transitar la tesis doctoral de la que procede el presente artículo.

Poco importa, para el presente artículo al menos, que la mayor parte de los análisis narratológicos se hayan centrado en textos de ficción o, como mucho, en aquellos que están en "las fronteras de la ficción" (Piñera Tarque, 2009: 272) como la autobiografía o el film documental. En casos como estos, el pacto pragmático que regula su construcción es el de la ficción. En el caso que nos ocupa, por contra, es el de la realidad. La dimensión narrativa de la televisión ha sido analizada muy sucintamente por Barroso García (1991: 492), que la ha descrito como una "narrativa de la realidad" o por Gordillo Rodríguez (1999), que, en otro trabajo, también se ha aventurado a estudiar las estructuras narrativas del informativo diario de televisión. Entre sus principales características, Cebrián Herreros (1978:189) destaca la inmediatez y la imprevisibilidad, factores que, como veremos, tendrán importantes consecuencias narrativas.

Compartimos la idea de que el texto analizado es un discurso porque en el informativo de televisión existe orden y selección (y una voluntad de coherencia narrativa), que, según Chatman (1990:28), son las principales características del discurso como categoría. Según la definición de Bal (1985:13), se trata de un texto porque es "un todo finito y estructurado que se compone de signos lingüísticos." Es más, según esta misma autora, y para concretar más, sería un texto narrativo, porque en él existe un agente que relata una narración. De hecho, desde el punto de vista narrativo, Cebrián Herreros (1978:279) ha definido el informativo de televisión como una unidad sintagmática yuxtapuesta.

La muestra analizada comprende varios informativos emitidos entre junio de 2006, cuando empezaron las emisiones regulares de la televisión autonómica de Asturias (TPA), y septiembre-octubre de 2010. En concreto, se han estudiado 19 TPA Noticias. Todos corresponden a la edición de las 20.30 de lunes a viernes, la primera que se puso en antena. Se ha procedido a una aproximación eminentemente fenomenológica. El autor ha visionado cada uno de esos textos con las herramientas de la narratología en la mano. Al modo de Vladimir Propp (1971) con los cuentos de hadas rusos, la investigación se ha fijado en que existe un "código implícito en el corpus de cada historia, un código que los lectores [...] conocen y esperan" (Chatman, 1990:95). Para el texto objeto de análisis la metodología de Todorov sobre el Decameron sí puede resultar de utilidad porque nos encontramos con una "repetición a gran escala, como en la lengua o el foklore." (Chatman, 1990:96). Lo que, siguiendo a Chatman, resultaría mecanicista a la hora de analizar otro tipo de discursos, sirve a esta investigación. En cada una de las emisiones diarias del informativo se encuentran las suficientes recurrencias como para que esta metodología sea de utilidad. 
Según Chatman (1990:87), "la recurrencia de relaciones es necesaria si hay que identificar una estructura narrativa. [...] No se puede hablar de la estructura de un relato si nos limitamos únicamente a ese relato.”

\section{Monólogo y diálogo en el informativo de televisión.}

En contra de lo que podría parecer a primera vista, en el tipo de texto analizado se observa un notable predominio de la palabra sobre la imagen. Lo confirma el lugar decisivo que ocupan los rótulos, la prioridad otorgada a la dimensión puramente informativa de los vídeos y, sobre todo, el papel central del narrador-presentador. Al contrario de lo que ocurre en el cine, sin embargo, las formas monologales están más presentes que las dialogales. Para empezar, el narrador-presentador se dirige al narratario-audiencia en forma de monólogo. No se puede hablar de diálogo porque no existe un "intercambio alternante, directo, inmediato, personal y dialéctico" (García Jiménez, 1993:215). Aún así, se pueden detectar intervenciones que aspiran a reproducir la forma dialogada. Son aquellas en las que el narrador principal (el presentador o presentadores) interactúa con los subnarradoresredactores, como se puede apreciar en el siguiente ejemplo:

Presentador-Narrador: "Emilio Pérez Touriño llegaba esta mañana a Asturias con motivo de la Cumbre Asturgalaica, cuyas mesas de trabajo continúan a estas horas en el Hotel de la Reconquista de Oviedo. Buenas tardes. En el exterior del hotel se encuentra María Herero. María, buenas tardes. ¿De qué se ha hablado hoy en esta cumbre?"

Redactor-Subnarrador: "Hola Buenas Tardes. Pues se ha hablado de muchos asuntos. De infraestructuras, de cultura, de educación, de administración, todo ello dividido en siete mesas sectoriales. En algunas de ellas, todavía se continúa trabajando a estas horas ...”(15-02-07)

Y también los intercambios entre dos narradores-presentadores, se produzcan en el seno de un mismo set o entre platós ubicados en lugares distintos. 
Presentador-Narrador a) : "Y en los deportes, el Sporting ha vuelto al trabajo con toque de atención. Loreto, buenas tardes ..."

Presentador-Narrador b): "Buenas tardes, Diana. Y es que a pesar de la victoria del sábado, en Ponferrada, por tres a cero ... “ (25-09-09)

En el caso de algún narrador-presentador, finalmente, la frecuencia en el monólogo de las marcas que remiten al autor implícito resta consistencia al personaje-narrador-presentador, de forma que ese uso particular de la técnica del monólogo genera en realidad personajes monologantes, es decir, aquellos en los que el verdadero hablante es el autor.

Presentador-Narrador: "Tomamos nota del tenso intercambio de pareceres entre España y Venezuela. El ministro del Interior de nuestro país confía en en el Gobierno de Chaves pero le pide más colaboración. Más excéptico todavía se ha mostrado el embajador venezolano en Madrid, quien había llegado a decir que tenía serias dudas de que los presuntos terroristas declarasen voluntaramiente haber sido entrenados en Venezuela. Más tarde, se ha matizado asimismo para aclarar que nunca ha acusado a España de torturas" (05-10-10)

El resto de personajes que no son ni narradores ni subnarradores intervienen asimismo en forma más monologal que dialogal, aunque sean monólogos que la selección del autor haya reducido a apenas quince segundos y aunque la intención de éste sea precisamente hacerlos dialogar, como sucede, a continuación, en el caso de los personajes 1 y 2.

Presentador-Narrador: "Menos sorpresas ha dado en su jornada final el Debate de Orientación Política. Los partidos que sustentan al Gobierno han aprobado la inmensa mayoría de resoluciones que han presentado. 
Destaca la aprobación de una propuesta sobre la Ley de la Función Pública con la que solucionar el pago a cuenta de la carrera profesional. PP e Izquierda Unida han coincidido en una que reclama un calendario de obras al Gobierno central. PSOE y PP no han coincidido en nada y así lo argumentan":

Personaje 1: "Y eso que lo hemos mirado detenidamente tratando de encontrar cuál es la aportación positiva, el compromiso que podía tener el Partido Popular con esta situación. Y la respuesta que hemos encontrado es que no quieren".

Personaje 2: "No trasladan en Proposición, en Propuestas de resolución nada de lo que, sobre lo que circuló todo el debate. Ni les preocupa la vivienda ni les preocupan los jóvenes ni les preocupa el empleo. Para nada ¿no?.” (25-09-09)

El procedimiento se parece al que emplea Alain Resnais en Hiroshima mon amour (1959) al introducir los diálogos del original de Marguerite Duras como si, en realidad, fuesen monólogos alternados. Pero, además, en el informativo de televisión objeto de este análisis se manifiestan varios tipos de monólogos más. Cuando el personaje está sólo en la escena, sea éste el narrador, los subnarradores o el resto de intervinientes, el monólogo es de tipo simple equivalente, dado que quienes monologan se dirigen en realidad a otro personaje que permanece en off, el narratario. Si, quienes hablan, no postulasen la existencia de este otro personaje, el monólogo sería simple-dramático. El siguiente es un ejemplo de un, para los estándares de la televisión, largo monólogo, dado que, en ningún momento, la intervención del subnarrador resulta interrumpida por al menos un personaje, como acostumbra a suceder en el resto de relatos de este tipo:

Redactor-Subnarrador: "Guardias Civiles vestidos de paisano controlarán desde hoy las zonas de mayor riqueza forestal de Asturias. Su labor será identificar tanto de día como de noche a los vehículos y 
personas que accedan al monte. También habrá patrullas uniformadas, agentes del SEPRONA y hasta un helicóptero de la Guardia Civil. Todo ello forma parte del Plan aprobado esta mañana por la Junta de Seguridad que preside el Delegado del Gobierno, Antonio Trevín. La consigna es mantener una actitud de tolerancia cero con los pirómanos y evitar que se produzcan incendios como el que ha amenazado la Reserva Natural de Muniellos en los últimos días. La Brigada de Investigación recopila aún los datos necesarios para aclarar las causas del fuego, pero no dudan de que ha sido intencionado. Cinco focos que se encendieron muy cerca de la carretera y casi al mismo tiempo dan la pista. El resultado provisional, casi 220 hectáreas quemadas y tres días de intensos trabajos en los que las dificultades del terreno y la inestabilidad del viento hicieron peligrar la seguridad de quienes trabajaban en las labores de extinción. A estas horas, los bomberos comprueban que no quede ningún rescoldo que haga rebrotar las llamas." (09-06-06)

En algunos casos, además, aunque muy excepcionales, el personaje monologante está acompañado, si bien su acompañante, por la razón que sea, no interviene. Es la situación que se origina cuando dos presentadores-narradores permanecen en el plano, aunque sólo uno de ellos interviene. Esta modalidad, que no acostumbra a ser utilizada porque introduce un tipo de expresividad que no conviene a los objetivos del texto, es la propia del monólogo simple incidental, más común en la obra de Dostoievski. En el siguiente fragmento, cuando el presentador a) narra, el presentador b) calla, pero permanece en la imagen. Del mismo modo, cuando el presentador b) inicia su intervención, es el presentador a) el que permanece en silencio, aunque en ningún momento desaparezca de la pantalla:

Presentador-Narrador a): "Buenas tardes. Las reacciones políticas a la propuesta de la Comisión Europea sobre el reparto de los fondos europeos no se ha hecho esperar. El Gobierno del Principado considera que los 700 millones que recibirá Asturias hasta 2007 mantendrán la convergencia con Europa. El Partido Popular, sin embargo, considera 
que son el resultado de una negociación nefasta.”

Presentador-Narrador b), "Y sin alejarnos del ámbito económico, hoy hemos sabido que la inflación se incrementó en Asturias en un 0.3 por ciento. La gasolina, el calzado y la ropa han sido los causantes de esta subida. Aún así, el incremento es un punto inferior a la media de toda España. Este martes, 13 de junio, nos ha dejado otras noticias que les adelantamos en el sumario." (13-06-06)

Cuando esta situación se da en un noticiario como el analizado la narración se convierte en descripción. Se produce también cuando un narrador que ya ha intervenido permanece demasiado tiempo en plano, como puede suceder durante la ejecución de un dúplexi ${ }^{\mathrm{i}}$ Su presencia se convierte en un elemento espurio a la diégesis. Finalmente, extrañas resultan también en este tipo de texto las distasias conativas, una modalidad de aparte escénico en la que un determinado monologante se dirige al espectador. En el informativo de televisión esto sucede cuando lo hace un personaje que no ha sido habilitado para hacerlo por la lógica narrativa, es decir, cuando participa de esta práctica un monologante que no es ni el personaje-narrador ni los personajes-subnarradores, pero sí es un personaje. En el texto analizado, acostumbran a ser representantes de la clase política.

La modalidad más propia de un informativo de televisión es, según García Jiménez (1993:211), el monólogo alternado, entendido como aquel en el que "dos o más personajes se suceden y permutan, sin llegar a constituirse en diálogo.” Es la modalidad característica de las formas en que intervienen en la diégesis el narrador y los subnarradores:

Presentador: "Los grupos parlamentarios han interpretado de diferente forma el resultado de este debate. Izquierda Unida considera que las medidas aprobadas son necesarias para salir de la crisis. El PSOE también comparte esta opinión y reprocha al PP no haber sido más constructivo. Los populares responden que lo aprobado debería haber sido más concreto." 
Redactor-Subnarrador: "Las treinta medidas aprobadas de forma conjunta por Izquierda Unida y PSOE se incluirán en los Presupuestos regionales de 2010. Dice Jesús Iglesias que servirá para fomentar el empleo y para garantizar las prestaciones sociales. Pero no sólo para eso:" (25-09-09)

$[\ldots]$

Presentador-Narrador: "Estas son las primeras imágenes del otoño en las que se pueden seguir con relativa proximidad los movimientos de un oso. En realidad es una osa localizada en los últimos días en la sierra de Caranga, en el concejo de Proaza. El estudio de esta imágenes ha permitido descartar que porte un lazo la osa, un lazo alrededor del pecho, en el que sí se puede descubrir una herida ya cicatrizada, causada por una trampa. (06-10-10)

Redactor- Subnarrador: “7:43 de la mañana. Un autobús escolar con siete niños a bordo se dirige al Instituto Fleming de Oviedo. Desciende el alto de Pedroveya con buena visibilidad y el piso mojado por el rocío. En las proximidades de la localidad de Villar, el conductor, de 24 años, divisa una furgoneta que asciende en sentido contrario por un tramo muy estrecho. Todo parece indicar que, tras pisar el freno y colisionar con la furgoneta, pierde el control del autobús. Tienen tiempo de recomendar a los niños que se agarren antes de precipitarse por un terraplén de unos diez metros. (15-06-06)

\section{$[\ldots]$}

Presentador-Narrador: "División de opiniones sobre la nueva propuesta de la Comisión Europea para el reparto de los fondos estructurales. Para el Gobierno del Principado, los setecientos millones que recibirá Asturias entre 2007 y 2013 permitirán seguir creciendo. El Partido 
Popular cree que se han perdido mil millones de euros por una mala negociación."

Redactor-Subnarrador: "El Principado considera que el volumen de ayudas que recibirá Asturias en el nuevo periodo 2007-2013 permitirá a la región mantener la convergencia con Europa. Pese a que ha perdido fondos por el denominado efecto estadístico, el Gobierno destaca que además de estos fondos regionales Asturias recibirá otro tipo de ayudas fundamentales para el fomento de la actividad industrial y el crecimiento de la economía." (13-06-06)

Pero, además, también es constatable la presencia de lo que este mismo autor llama monólogos complejos. Sería la práctica detectable en el interior de las subnarraciones, la forma en que aparecen los personajes que monologan en forma de total $l^{i i}$.

Redactor-Subnarrador: "Las treinta medidas aprobadas de forma conjunta por Izquierda Unida y PSOE se incluirán en los Presupuestos regionales de 2010. Dice Jesús Iglesias que servirá para fomentar el empleo y para garantizar las prestaciones sociales. Pero no sólo para eso:"

Personaje 1. "Para revalidar el acuerdo de Gobierno alcanzado hace menos de un año, ratificar el compromiso del Gobierno de Asturias de cumplir los contenidos de ese acuerdo de Gobierno."

"Aunque en el PP no interpretan las votaciones de hoy de la misma manera. Los populares creen que a las propuestas aprobadas les falta concreción y que es algo buscado por Izquierda Unida y PSOE."

Personaje 2. "No quiero hacer propuestas porque después me van a llamar mentiroso. ¿No?. Yo creo que esto es un poco lo que le pasa al Partido Socialista y a Izquierda Unida, en este Gobierno compartido, 
con dos cabezas, y que no tiene ya ninguna confianza en el proyecto del señor Areces."

"Algo que rechazan los socialistas que acusan al PP de no presentar medidas constructivas:"

Personaje 3. "Se están alejando de la relación con el resto de la fuerzas políticas de aquí, de la relación con el Gobierno. Y de los intentos de relacionarse también con las ideas que han trasladado empresarios y sindicatos a la concertación regional. No coinciden con nadie."

"Fernando Lastra asegura además que la dirección del PP también se ha distanciado de los alcaldes del partido por mantener posturas diferentes sobre el Plan A de financiación a los municipios." (25-09-09

Finalmente, cabría incluir la modalidad de relato que ofrecen tanto el narrador como los subnarradores en la propia del monólogo narrado y que consiste en el hecho de que:

“... las palabras y pensamientos de un personaje son narrados, es decir, contados por un narrador en tiempo pasado y en tercera persona. Es el erlebte Rede alemán. Discurso de narrador y discurso del personaje quedan vinculados por un recíproco compromiso: el narrador presta su voz y el personaje aporta el contenido y el tono del discurso narrativo (García Jiménez, 1993:213)”

El siguiente es un ejemplo altamente ilustrativo de esta práctica:

"Presentador-Narrador: El consejero de Justicia, Francisco Javier García Valledor, ha reiterado hoy el malestar de su partido, Izquierda Unida, con el PSOE a causa del futuro nombramiento del Procurador General. Valledor ha acusado a socialistas y populares de ser un obstáculo para la regeneración democrática de Asturias

Redactor-Subnarrador: "Francisco Javier García Valledor, consejero de Justicia, de Izquierda Unida, afirma que la confianza en su socio de 
Gobierno está bajo mínimos. Califica de desleal el acuerdo que han alcanzado socialistas y populares para nombrar al Procurador General. Cree que detrás hay un reparto de cargos entre ambos partidos en la institución del Defensor del Pueblo de Asturias.

Personaje 1. Yo creo que esto además significa que estas dos fuerzas políticas son una rémora importante para la profundización democrática y la regeneración democrática en Asturias en estos momentos.

Para Ovidio Sánchez, Izquierda Unida ha utilizado escusas de patio de colegio para romper con el PSOE en la Junta General.

Personaje 2. Están a discusión cada quince días con el gobierno. Pero a quién quieren engañar si sabe todo el mundo que no van a marchar del Gobierno. Y los que más lo saben son sus propios compañeros de partido, que son los que se lo exigen.

Valledor confía en que las popuestas del Gobierno logren consenso antes de someterse a votación en la Cámara para evitar que los desencuentros afecten a la continuidad del pacto de Gobierno. Por eso, entienden que no hay razones para la división. El PSOE explicará su posición mañana." (14-06-06)

En definitiva, existe diálogo cuando un presentador-narrador intercambia una o varias frases con otro presentador-narrador, estén ambos en el mismo plató o en estudios diferentes. Y también existe una voluntad de diálogo cuando el presentador-narrador se dirige a un redactor-subnarrador en el marco de una conexión en directo, una intención que, sin embargo, demasiadas veces se queda en eso, en mero intento, dado que no llega a producirse una verdadera comunicación y todo queda en un simple desahogo expresivo, práctica que, como recuerda García Jiménez $(1993 ; 216)$, no tiene nada que ver con lo que, narrativamente, se entiende por diálogo. Desde una perspectiva narratológica, estas prácticas dialogales comparten algunos objetivos con las que aparecen en los géneros narrativos, pero 
también difieren en parte. Por ejemplo, en el texto objeto de este estudio no pretenden revelar las características psicológicas del personaje, como sí es usual en la tradición literaria. Sin embargo, de manera similar a como sucede en los géneros narrativos, estas formas dialogales sí aspiran a hacer más legible el texto, a reforzar la verosimilitud y a promover una mayor identificación del narratario con lo narrado.

Existen varias clases de diálogos (García Jiménez, 1993:225-226): los de comportamiento, los de escena, los diegéticos, los autoriales y los de referente lingüístico. Los primeros son aquellos puramente ambientales, que simplemente refieren generalidades. Los de escena y los autoriales son los más literarios. Los primeros, también conocidos como dramáticos o expresivos, pretenden revelar los pensamientos o intenciones del personaje. Los segundos acaban denotando la presencia del autor o de sus delegados en el texto, al configurarse como auténticos estilemas. Los de referente lingüísitico son aquellos que pretenden reproducir una determinada forma de expresión: el lenguaje de la calle, el de los medios de comunicación. Los que se observan en el texto objeto de este análisis, aunque, en el plano teórico, traten de aproximarse a esta última manifestación son, sin embargo, diegéticos, entendidos como aquellos que "desempeñan una función narrativa propiamente dicha, que afecta al motivo, desarrollo y desenlace de la acción principal, a las propiedades (orden y duración) del discurso" (García Jiménez, 1993:226).

Dentro de estas formas dialogadas existen también variantes que tienen más que ver con la naturaleza audiovisual del discurso. Efectivamente, en la narrativa de la imagen, además de una relación paradigmática, se aprecia asimismo una relación sintagmática. El diálogo no se produce sólo entre signos homogéneos (palabras), como sucede en la primera de las formas de la relación, sino que en el texto objeto de este estudio interviene una pluralidad de significantes:

"Los dialogantes aplican códigos de la comunicación no verbal (posturales, gestuales y expresivos). Los diálogos de cine son ante todo diálogos de la mirada. Más aún; en el juego de los dialogantes interlocutores (emisor y destinatario) que se apelan e implican recíprocamente, aparece, entre las burbujas del $<<$ espacio lector $>>$, el dialogatario, que asiste, con ventaja sobre los actores, a dos diálogos simultáneos: el de los personajes y el del espectáculo. El espectador de cine o de televisión observa con placer las redundancias, solapamientos, matizaciones y contrastes con que construye el realizador el juego interactivo entre el diálogo de los personajes y el diálogo del espectáculo fílmico. El lenguaje de la imagen a través de la focalización de las cámaras permite al espectador descubrir el significado dialógico de las alternancias" (García Jiménez, 1993:227) 
En las formas dialogales que se pueden localizar en el informativo de televisión, además de una voluntad de progresión dramática y de secuencialidad, se aprecia una estrategia discursiva de tensión psicológica. El formato de preguntas y respuestas pretende incrementar el interés del espectador introduciendo un cierto suspense.

\section{Conclusiones}

En el informativo de televisión hay, pues, más narración que mostración. Y, sin embargo, existe una diferencia importante. Al contrario de lo que sucede en el cine, en el informativo de televisión no es el diálogo el que monopoliza la retórica; es el monólogo, entendido como el discurso de un sólo personaje. El narrador-presentador se dirige al narratarioaudiencia en forma de monólogo. No es un soliloquio porque no se dirige a sí mismo. Y tampoco establece un diálogo porque no existe un intercambio directo y personal. En este sentido, las únicas intervenciones existentes en el relato analizado que se acercan a la forma dialogada son aquellas que el narrador principal (el presentador o presentadores) entabla con los subnarradores-redactores. $\mathrm{Y}$ también los intercambios entre dos narradorespresentadores, se produzcan en el seno de un mismo set o entre platós ubicados en lugares distintos.

Las modalidades dialogales que aparecen comparten algunos objetivos con las que han consagrado los distintos géneros narrativos, pero también difieren en parte. Por ejemplo, en el texto objeto de este estudio no pretenden revelar las características psicológicas del personaje, como sí es usual en la tradición literaria. Sin embargo, de manera similar a como sucede en los géneros narrativos, estas formas dialogales sí aspiran a hacer más legible el texto, a reforzar la verosimilitud y a promover una mayor identificación del narratario con lo narrado. En el informativo de televisión analizado se observan al menos cuatro situaciones dialogales, cada una de ellas con particularidades que afectan a lo que llega al dialogatario. La conversación entre dos narradores-presentadores en plató, la conversación entre estos mismos actores desde platós diferentes, el diálogo entre el narrador-presentador y un subnarrador a través de una pantalla de televisión (plasma) y el diálogo entre el narrador-presentador y un subnarrador a través de la pantalla de televisor del dialogatario (dúplex). 


\section{Bibliografía}

Bal, Mieke. (1985) Teoría de la narrativa (una introducción a la narratología). Madrid: Cátedra.

Bandrés, Elena; García Avilés, José A.; Pérez, Gabriel y Pérez, Javier. (2000) El periodismo en la televisión digital. Barcelona: Paidós.

Barroso, Jaime.(1991) La producción de la información de actualidad: forma y formato de la noticia. Madrid: Editorial de la Universidad Complutense de Madrid.

Cebrián Herreros, M. (1978) Introducción al lenguaje de la televisión. Una perspectiva semiótica. Madrid: Ediciones Pirámide.

Chatman, Seymour. (1990) Historia y discurso: la estructura narrativa en la novela y en el cine. Madrid: Taurus.

Chillón, Albert. (1994). L'estudi de les relacions entre periodisme y literatura per mitjà del comparatisme periodístico-literari. Anàlisi. Quaderns de comunicació y cultura, 16; 123150.

García Jiménez, Jesús (1993). Narrativa audiovisual. Madrid: Cátedra

Gaudreault, André y Jost, François. (1995) El relato cinematográfico. Barcelona: Paidós Comunicación.

Genette, Gérard. (1998). Nuevo discurso del relato. Madrid: Cátedra.

Greimas, Julien. (1987). Semántica estructural. Investigación metodológica. Madrid:

Editorial Gredos.

Gordillo, Inmaculada. (1999). Informativos en Andalucía. Estructuras narrativas del informativos diario en televisión. Granada: Junta de Andalucía. Consejería de Cultura.

Piñera Tarque, Ismael. (2009) Mundos narrativos. Relato literario y relato fílmico. Kassel: Edition Reichenberger.

Propp, Vladimir. (1971). Morfología del cuento. Madrid: Cátedra.

Todorov, Tzvetan. (1991). Los géneros del discurso. Caracas: Monte Ávila Latinoamericana Editores.

\footnotetext{
Según Bandrés et Al (2000:264), un “tipo de conexión, mediante un sistema de información que puede transmitir y recibir, simultáneamente dos mensajes. Transmisión de ida y vuelta.” En el caso particular de la televisión, se da cuando presentador y redactor aparecen al mismo tiempo en la pantalla, que se parte en dos, para que uno ocupe la derecha y el otro la izquierda.

ii Según Bandrés et Al (2000: 273). Un total es un "testimonio limpio de una o varias personas sobre un tema concreto en una información para televisión. Equivale a una declaración.”
} 